\title{
Подавление эффекта квазинасыщения вольт-амперных характеристик мощных сверхвысокочастотных латеральных транзисторов
}

\author{
(С) Р.П. Алексеев ${ }^{1}$, М.И. Черных ${ }^{1}$, А.Н. Цоцорин ${ }^{1}$, И.В. Семейкин ${ }^{1}$, Г.В. Быкадорова ${ }^{2}$ \\ ${ }^{1}$ Акционерное общество „Научно-исследовательский институт электронной техники“, \\ 394033 Воронеж, Россия \\ ${ }^{2}$ Воронежский государственный университет, \\ 394018 Воронеж, Россия \\ E-mail: arp@niiet.ru
}

Поступила в Редакцию 5 апреля 2021 г.

В окончательной редакции 12 апреля 2021 г.

Принята к публикации 12 апреля 2021 г.

Проведен анализ электропараметров нового поколения СВЧ LDMOS-транзисторов, разработанных AO „НИИЭТ“. Выявлено существенное подавление эффекта квазинасыщения переходной и выходной вольтамперной характеристики по сравнению с приборами предыдущего поколения. Сравнение с прибором зарубежного производства показывает, что достигнутые результаты близки к мировому уровню.

Ключевые слова: мощные CBЧ транзисторы, LDMOS-технология, квазинасыщение вольт-амперной характеристики.

DOI: 10.21883/FTP.2021.08.51141.9658

\section{1. Введение}

Начиная с 1990-х годов LDMOS (Laterally Diffused Metal Oxide Semiconductors) технология является доминирующей на рынке мощных СВЧ транзисторов. Развитие в последние годы технологий на основе широкозонных полупроводниковых материалов, в частности на нитриде галлия, привило к частичной потере LDMOS-транзисторами своих позиций, тем не менее о прекращении их развития и тем более производства в обозримом будущем говорить не приходится. Так, зарубежные производители LDMOS-транзисторов в настоящее время начали осваивать диапазон частот до 5 ГГц [1], традиционно отводимый под приборы на основе нитрида галлия и арсенида галлия.

Одной из проблем LDMOS-транзисторов, мало освещенной в отечественной литературе, является эффект квазинасыщения (анг. Quasi-saturation) вольт-амперных характеристик (BAX) [2]. Эффект квазинасыщения ВАХ LDMOS-транзистора может быть представлен как два отдельных, но взаимосвязанных эффекта: квазинасыщение переходной BAX и квазинасыщение выходной BAX. Квазинасыщение переходной ВАХ заключается в появлении на ВАX участка слабой зависимости тока стока $I_{D}$ от напряжения на затворе $U_{G}$ при достижении $U_{G}$ определенного значения. Это объясняется тем, что при некотором значении напряжения на затворе плотность инжектированных носителей заряда превысит концентрацию примеси в относительно слабо легированной LDD (Lightly Doped Drain) области. При дальнейшем повышении $U_{G}$ суммарное поле носителей заряда начинает экранировать исток от напряжения на стоке $U_{D}$. Таким образом, повышение напряжения на затворе уменьшает тянущее поле стока, что в конечном итоге вызывает насыщение переходной ВАХ, независимо от того достигла ли дрейфовая скорость носителей заряда насыщения или нет [3].

Квазинасыщение выходной ВАХ заключается в отсутствии на ней участка идеального насыщения: BAX прибора подобна характеристике классического короткоканального MOS-транзистора. Как и в MOS-транзисторах, в LDMOS-транзисторах насыщение выходной характеристики вызывается достижением насыщения дрейфовой скорости носителей заряда. Однако в LDMOSтранзисторах скорость носителей достигает максимума не в канале, а в том или ином участке LDD-области (в зависимости от значения $U_{G}$ ) и не может вызвать полного насыщения тока стока [4].

Квазинасыщение переходной и выходной ВАХ мощного LDMOS-транзистора невозможно полностью подавить, однако подбором конструктивно-технологических параметров его проявление можно существенно ослабить.

\section{2. Возможные пути ослабления эффекта квазинасыщения}

АО „НИИЭТ“ совместно с ПАО „Микрон“ за счет собственных средств провел инициативные работы по модернизации и оптимизации конструкции СВЧ LDMOS-транзисторов собственной разработки с целью соответствовать уровню ведущих зарубежных производителей. Проведенная работа позволила добиться существенного улучшения основных как электростатических (напряжение пробоя сток-исток, сопротивление 


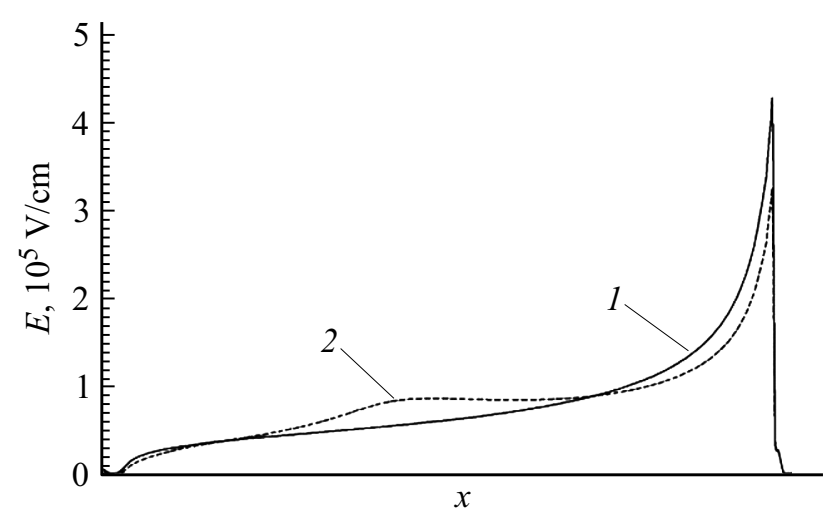

Рис. 1. Распределение напряженности электрического поля вдоль LDD-области $\left(U_{D}=50 \mathrm{~B}, U_{G}=15 \mathrm{~B}\right): 1$ - без полевого электрода, $2-$ с полевым электродом.



Рис. 2. Распределение напряженности электрического поля вдоль LDD-области при разных положения HDD-участка: 1 - без HDD, 2 - HDD около затворного края LDD-области, 3 - HDD в середине LDD-области, 4 - HDD около стокового края LDD-области.

сток-исток в открытом состоянии, ток стока насыщения), так и энергетических (максимальная выходная мощность, коэффициент усиления мощности, коэффициент полезного действия стока) параметров приборов [5]. Однако внесенные конструктивные изменения были направлены не только на повышение основных параметров транзистора, но и на подавление нежелательных физических эффектов, происходящих при работе транзистора, в том числе эффект квазинасыщения ВАХ.

Одним из конструктивных элементов, способных в наибольшей степени повлиять на степень выраженности квазинасыщения, является полевой электрод. Во-первых, включение полевого электрода позволяет повысить концентрацию примеси в LDD-области, что обусловлено ростом оптимальной концентрации примеси, при которой напряжение пробоя сток-исток достигает максимума. Повышение концентрации примеси в LDD-области является наиболее эффективным способом ослабления эффекта квазинасыщения. Во-вторых, наличие полевого электрода приводит к перераспределению напряженности электрического поля в LDD-области (рис. 1), в результате чего основной пик напряженности электрического поля уменьшается, появляется дополнительный пик, соответствующий положению края полевого электрода.

Варьируя протяженность полевого электрода, толщину межслойного диэлектрика под ним, а также меняя его конструкцию (ступенчатая, многослойная и др. [6]), можно добиться более равномерного распределения напряженности поля при том или ином напряжении на затворе $U_{G}$, что способствует подавлению квазинасыщения.

Другим способом ослабления эффекта квазинасыщения является формирование сложного профиля легирования LDD-области [6]. Как и в случае с полевым электродом, меняя протяженность LDD-области, концентрацию легирующей примеси и положение высоколегированного участка (HDD), можно добиться требуемого распределения напряженности поля вдоль LDD-области. Пример того, как сильно может меняться распределение напряженности поля, приведен на рис. 2.

\section{3. Полученные результаты}

Подбором вышеописанных конструктивно-технологических параметров удалось достичь существенного ослабления эффекта квазинасыщения. На рис. 3 приведена переходная BAX LDMOS-транзисторов новой ревизии в сравнении с характеристикой прибора предыдущего поколения. Оба транзисторных кристалла выполнены в одном форм-факторе, характеризуются одинаковым периметром затвора и собраны идентичным образом. Разница в значении тока стока насыщения заключается в большей удельной мощности новой конструкции.

Как видно из рис. 3, внесенные изменения позволили достичь более резкого насыщения переходной характеристики. Также возросла крутизна на линейном участке.

Семейства выходных ВАХ транзисторов предыдущей и новой разработки продемонстрированы на рис. 4. Так

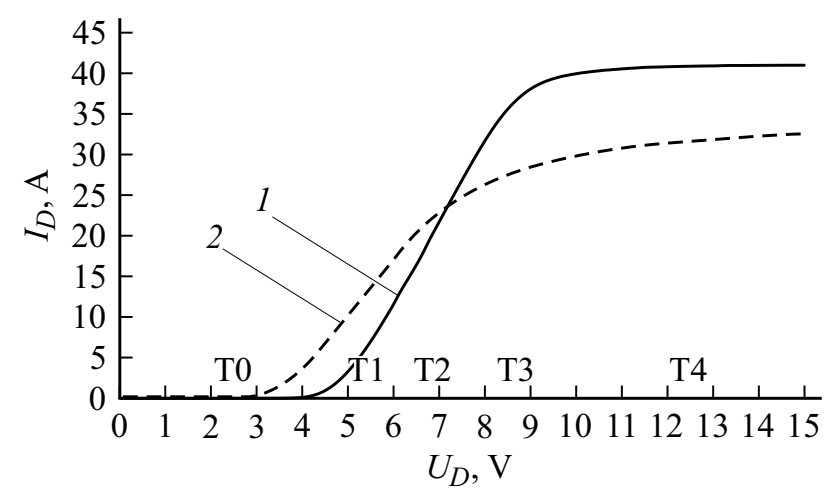

Рис. 3. Выраженность квазинасыщения переходной ВАХ на приборах новой (1) и предыдущей (2) конструкции. 

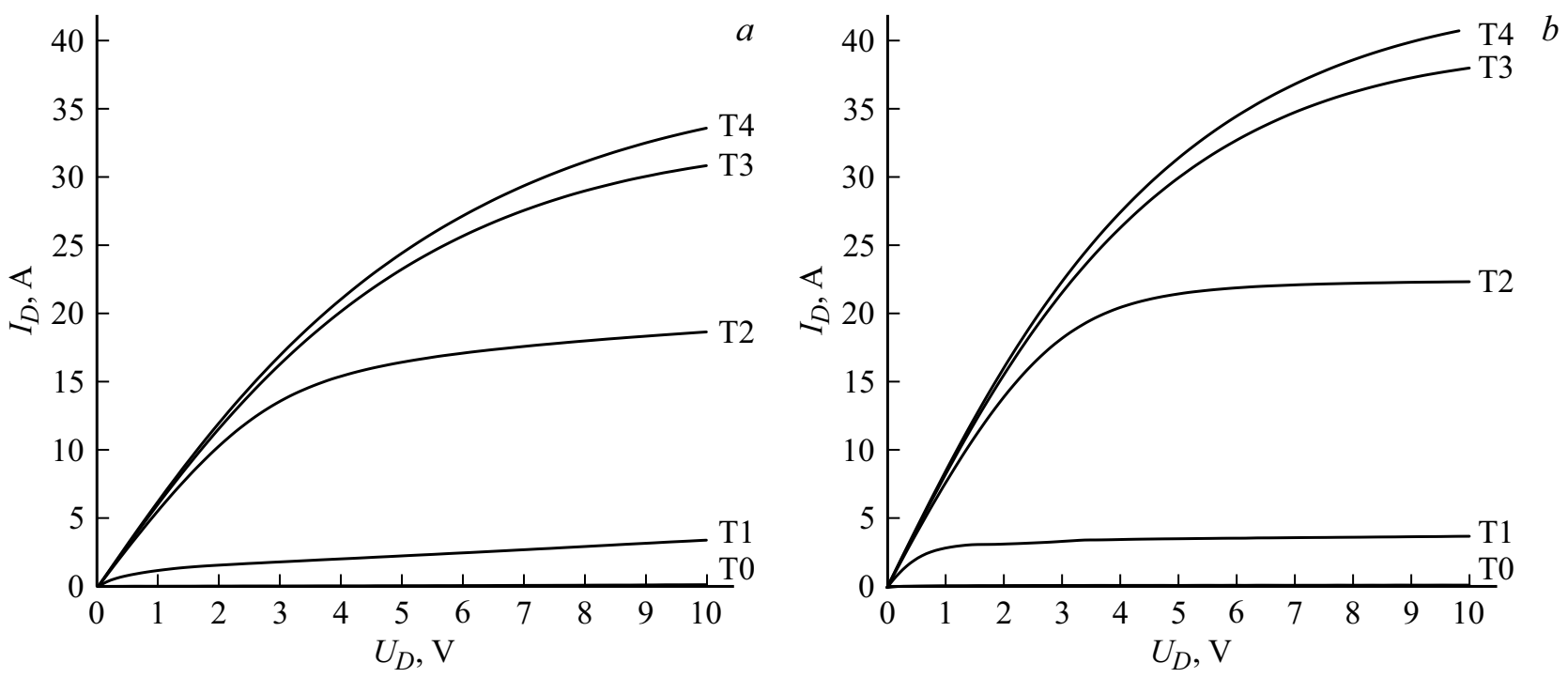

Рис. 4. Семейства выходных ВАХ приборов: $a-$ предыдушей конструкции, $b-$ новой конструкции.

Дифференциальные сопротивления LDMOS-транзисторов

\begin{tabular}{c|c|c|c}
\hline \multicolumn{4}{c}{$R_{\text {out }}\left(U_{D}=8 \mathrm{~B}\right)$, Ом } \\
\hline $\begin{array}{c}\text { Участок } \\
\text { переходной ВАХ }\end{array}$ & $\begin{array}{c}\text { Предыдущая } \\
\text { конструкция }\end{array}$ & $\begin{array}{c}\text { Новая } \\
\text { конструкция }\end{array}$ & BLF188XR \\
\hline T1 & 12.0 & 102.5 & 68.3 \\
T2 & 49.1 & 254.4 & 137.1 \\
T3 & 23.9 & 30.4 & 18.2 \\
T4 & 20.3 & 25.5 & 15.8
\end{tabular}

как сравниваемые приборы имеют различный уровень порогового напряжения, значения напряжения на затворе при построении выходных ВАХ выбирались не одинаковыми по значению, а одинаковыми по положению на переходной ВАХ. Первая точка Т0 находится на подпороговом участке, вторая точка T1 - в начале линейного участка, Т2 лежит на середине линейного участка, Т3 находится на переходе линейного участка в насыщение, Т4 - на участке полного насыщения переходной BAX (на рис. 3 отмечены точки для новой конструкции).

Для большей наглядности в таблице приведены дифференциальные выходные сопротивления $R_{\text {out, }}$ рассчитанные по приведенным BAX в точке $U_{D}=8 \mathrm{~B}$. Также для сравнения указаны значения $R_{\text {out }}$ для транзистора BLF188XR производства фирмы Ampleon [7]. Так как рассматриваемые транзисторы обладают разным значением тока стока насыщения, в таблице при расчете дифференциального сопротивления использовался нормированный ток:

$$
R_{\text {out }}=\mathrm{d} U_{D} / \frac{\mathrm{d} I_{D}}{I_{D}}=\frac{I_{D} \mathrm{~d} U_{D}}{\mathrm{~d} I_{D}}
$$

\section{4. Заключение}

По данным таблицы видно, что внесенные изменения в конструкцию LDMOS-структуры привели к существенному подавлению эффекта квазинасыщения выходной $\mathrm{BAX}$, особенно при напряжениях на затворе, соответствующих линейному участку переходной ВАХ (точки Т1 и Т2). Сравнение с зарубежным аналогом показывает, что достигнутые результаты близки к мировому уровню.

Таким образом, усовершенствованная конструкция LDMOS-транзисторов AO „НИИЭТ“ позволяет не только повысить их энергетические параметры, но и добиться снижения выраженности негативного эффекта квазинасыщения переходной и выходной вольт-амперных характеристик СВЧ-транзисторов.

\section{Финансирование работы}

Работа проводилась в рамках НИР „Исследование и разработка мощных CBЧ LDMOS-транзисторов с повышенным коэффициентом полезного действия в L-диапазоне частот и транзисторов на основе нитрида галлия для работы в L-, S- и C-диапазонах частот“ за счет собственных средств АО „НИИЭТ“.

\section{Конфликт интересов}

Авторы заявляют, что у них нет конфликта интересов.

\section{Список литературы}

[1] S.J.C.H. Theeuwen, H. Mollee, R. Heeres, F. Van Rijs. EDI CON 2019 Beijing, April 2.

[2] B.K. Sampath, M. Shrivastava. IEEE Trans. Electron Dev., $65(1), 191$ (2018). 
[3] Р.П. Алексеев, А.Н. Цоцорин, Е.Н. Бормонтов, Г.В. Быкадорова. Электрон. техн., сер. 1, СВЧ-техника, 543 (4), 6 (2019).

[4] Р.П. Алексеев, А.Н. Цоцорин, Е.Н. Бормонтов, Г.В. Быкадорова. Электрон. техн., сер. 1, СВЧ-техника, 543 (4), 15 (2019).

[5] Р.П. Алексеев, А.Н. Цоцорин, М.И. Черных. Электроника НТБ, 00195 (4), 98 (2020).

[6] Р.П. Алексеев, Е.Н. Бормонтов, Г.В. Быкадорова, А.Н. Цоцорин. В сб.: Радиолокация, навигация, связь. Матер. 24-й Междунар. науч.-техн. конф. (Воронеж, Изд-во Вэлборн, 2018) т. 5, с. 257.

[7] Сайт фирмы Ampleon [Электронный pecypc]. (https://www.ampleon.com) (дата обращения 31.03.2021).

Редактор А.Н. Смирнов

\section{Suppression of the effect of quasi-saturation of current-voltage characteristics of power radio frequency lateral transistors}

R.P. Alekseev ${ }^{1}$, M.I. Chernykh ${ }^{1}$, A.N. Tsotsorin ${ }^{1}$, I.V. Semeikin ${ }^{1}$, G.V. Bykadorova ${ }^{2}$

1 Joint-Stock Company

„Scientific Research Institute of Tlectronic“,

394033 Voronezh, Russia

${ }^{2}$ Voronezh State University,

394018 Voronezh, Russia

Abstract Was been performed the analysis of electric parameters of a new generation of RF LDMOS transistors developed by JSC „NIIET“. In comparison with the devices of the previous generation was revealed a significant suppression of the effect of quasi-saturation of $I_{D}-U_{G}$ and $I_{D}-U_{D}$ characteristics. Comparison with a foreign-made device shows that the achieved results are close to the world level. 